\title{
The effect of ruminal phosphate concentration on the absorption of calcium, phosphorus and magnesium from the reticulo-rumen of the sheep
}

\author{
BY L. J. BEARDSWORTH, P. M. BEARDSWORTH AND A. D. CARE* \\ Department of Animal Physiology \& Nutrition, University of Leeds, Leeds LS2 9JT
}

(Received 4 September 1987 - Accepted 10 January 1989)

\begin{abstract}
1. The absorption rates of calcium, inorganic phosphate $\left(\mathrm{P}_{\mathrm{i}}\right)$ and magnesium were determined from buffered solutions placed in the temporarily isolated and washed reticulo-rumen of conscious sheep. The basic composition of these solutions was similar to that found in supernatant fractions of ultracentrifuged rumen contents.

2. The $P_{i}$ concentrations studied in these solutions were $2,8 \cdot 7,14,17 \cdot 3$ and $38 \mathrm{mmol} / 1$. The initial concentration of $\mathrm{Ca}$ was $2.0 \mathrm{mmol} / 1$ and that of $\mathrm{Mg}$ was $2.5 \mathrm{mmol} / 1$ in all experiments.

3. Increasing the $P_{i}$ concentration in the rumen solution from 2 to $38 \mathrm{mmol} / 1$ resulted in increases in the net absorption rates of both $\mathrm{Ca}$ and $\mathbf{P}_{i}$, and a decrease in the potential difference across the wall of the rumen.

4. Similarly, increasing the $P_{i}$ concentration from 2 to $17.3 \mathrm{mmol} / 1$ resulted in an increase in the net absorption rate of $\mathrm{Mg}$ from the rumen.

5. Mineral analysis of strained rumen fiuid or a $30000 \mathrm{~g}$ centrifugate of strained rumen fluid revealed a reduced $P_{i}$ concentration in sheep fed on frozen spring grass as opposed to the pellet + hay diet. The values obtained were within the range studied.
\end{abstract}

There is recent in vitro evidence to suggest that inorganic phosphate $\left(P_{i}\right)$ ions are absorbed across the reticulo-rumen (Breves et al. 1986, 1988). The extent of this $P_{i}$ absorption appears to be dependent on the $P_{1}$ concentration in the rumen, within the range $0-15$ mmol/l. Similarly, net $P_{1}$ absorption from the omasum has also recently been described (Edrise \& Smith, 1986).

Grazing ruminants may experience suboptimal phosphorus intakes on spring grass (Ritchie \& Fishwick, 1977) and hypophosphataemia has been reported to develop during hypomagnesaemic tetany (Simesen, 1970). Another feature common to the condition of clinical hypomagnesaemia is hypocalcaemia (Hemingway \& Ritchie, 1965).

The current study was undertaken to investigate the relation between the absorption rates of calcium, $P_{i}$ and magnesium from the isolated reticulo-rumen at different rumen $P_{i}$ concentrations. The $P_{i}$ concentrations used were within the physiological ranges for $P$ replete and P-depleted sheep (G. Breves, personal communication).

\section{MATERIALS AND METHODS}

Anaesthesia and surgery. Seven large crossbred ewes and wethers were prepared with large rumen fistulas. The sheep used were 1.5-5 years of age. The rumen fistulas were established under halothane-oxygen anaesthesia, following induction of anaesthesia by an intravenous injection of thiopentone (Pentothal; May \& Baker).

Experimental protocol. The sheep were trained for use in the temporarily isolated, washed rumen technique (Martens \& Rayssiguier, 1980; Care et al. 1984). Briefly, this technique involved restraining the conscious sheep by a loose neck yoke and removing the rumen cannula and rumen contents. The contents were stored at $40^{\circ}$ until the end of the experiment when they were returned to the sheep. Washing buffer ( 2 litres), at $40^{\circ}$, was poured into the rumen and agitated manually in order to dislodge material from the rumen

\footnotetext{
* For reprints.
} 
epithelium. The buffer was removed by suction and the procedure repeated until the effluent was free from rumen contents. The washed rumen was isolated according to Martens \& Rayssiguier (1980). The base of the oesophagus was temporarily occluded by an inflated cuff, and the saliva collecting cranial to the obstruction was withdrawn by continuous suction. This was pumped into the abomasum via a Foley catheter (Eschmann; 75-100 ml, 30 catheter, $10.0 \mathrm{~mm}$ ) passing through the reticulo-omasal orifice, the cuff being inflated in the abomasal entrance to complete the seal. The oesophageal cuff was connected to a nasogastric tube, which was anchored at the nasal end once the cuff was situated in the appropriate place (80-100 $\mathrm{mm}$ from the distal end of the oesophagus). Air was allowed to bleed into the lower oesophagus in order to prevent the oesophagus from collapsing and occluding the outflow of saliva. The experimental solutions were introduced into the isolated, washed reticulo-rumen, and continually gassed with carbon dioxide via a tube fitted with a diffusing nozzle.

During an experiment, the fistula in the rumen was sealed by inner and outer foamrubber flanges held together by plastic tapes tied externally. Tubes for saliva collection and re-circulation, $\mathrm{CO}_{2}$, and the air bleed to the saliva collector, ran through both flanges.

Between experimental observations, sheep were usually maintained on $1 \mathrm{~kg}$ commercial pelleted diet $(500 \mathrm{~g}$ dried grass and $500 \mathrm{~g}$ beet pulp $/ \mathrm{kg}$, with added trace elements) plus chopped hay.

Sheep were not fed in the morning before an experiment which began at 07.00 hours. Sheep were always used in pairs, to minimize stress due to isolation, and stood in crates for the whole day. The sheep were fed after completion of the experiment ( 21.00 hours), and food and water were consumed readily. These sheep were left for at least $7 \mathrm{~d}$ before re-use. The experimental environmental conditions were kept as constant as possible.

Measurement of potential difference $(P D)$ across the rumen wall. The method used was that of Dobson (1959), except that blood was not allowed to clot in the venous catheter but was mixed with heparinized saline $(9 \mathrm{~g}$ sodium chloride/l) to facilitate repeated observations. The sheep were prepared with jugular venous catheters on the day before an experiment, and the PD was recorded between the rumen contents and the venous blood by means of electrodes ( $40 \mathrm{~g}$ agar $/ 1$ in saturated potassium chloride) connected to calomel half cells and a high impedance millivolt-meter.

Solutions used to measure mineral absorption rates. The compositions of solutions used for mineral absorption studies are displayed in Table 1, and are based on mineral analyses of supernatant fractions of centrifuged rumen contents.

Before each mineral absorption period was begun, 2 litres of the experimental solution to be used was placed in the rumen to equilibrate for up to $20 \mathrm{~min}$. The solutions were heated to $40^{\circ}$ and contained CrEDTA as a fluid marker. This was prepared according to Downes \& McDonald (1964). The $\mathrm{pH}$ of the solution was adjusted, using $\mathrm{CO}_{2}$, to $6 \cdot 6-6 \cdot 8$ before use. In the case of the higher phosphate solutions the mean $\mathrm{pH}$ was reduced to $6 \cdot 2$.

Measurement of mineral absorption rates. The equilibrium solution was removed under suction and a $10 \mathrm{ml}$ portion of the test solution was taken as the original sample. Of this solution, 2 litres were immediately placed into the rumen and another $10 \mathrm{ml}$ sample taken $5 \mathrm{~min}$ later - the time-zero sample. Sampling was repeated at 30 and $60 \mathrm{~min}$. The remaining solution was then removed and its volume noted.

The absorption rate of the mineral ( $\mathrm{mmol} / 2$ litres per $\mathrm{h}$ ) was calculated according to Grace et al. (1988) and assumes that CrEDTA is a non-absorbable substance at normal osmotic pressure (Dobson et al. 1976).

Mineral analyses. $\mathrm{Mg}, \mathrm{Ca}$ and CrEDTA concentrations were determined by atomic absorption spectrophotometry (Instrumentation Laboratory 151). The ionized $\mathrm{Ca}$ concentration was determined by use of a Ca-sensitive electrode (Nova 2; Clandon 
Table 1. Composition of intraruminal solutions of differing phosphate concentration $(\mathrm{mmol} / \mathrm{l})$

\begin{tabular}{lccccccc}
\hline \hline Phosphate & 2 & $8 \cdot 7$ & 14 & $17 \cdot 3$ & 38 & 2 & 20 \\
\hline Sodium & 108 & 108 & 108 & 110 & 108 & 60 & 60 \\
Potassium & 30 & 30 & 30 & 30 & 30 & 90 & 90 \\
Calcium & 2 & 2 & 2 & 2 & 2 & 2 & 2 \\
Magnesium & $2 \cdot 5$ & $2 \cdot 5$ & $2 \cdot 5$ & $2 \cdot 5$ & $2 \cdot 5$ & $2 \cdot 5$ & $2 \cdot 5$ \\
Ammonium & 10 & 10 & 10 & 10 & 10 & 10 & 10 \\
Chloride & 80 & 80 & 80 & 80 & 80 & 80 & 84 \\
Bicarbonate & 45 & 39 & 33 & 20 & 20 & 45 & 45 \\
Acetate & 30 & 30 & 30 & 30 & 30 & 30 & 30 \\
Propionate & 10 & 10 & 10 & 10 & 10 & 10 & 10 \\
Butyrate & 5 & 5 & 5 & 5 & 5 & 5 & 5 \\
Total cations & $152 \cdot 5$ & $152 \cdot 5$ & $152 \cdot 5$ & $154 \cdot 5$ & $152 \cdot 5$ & $164 \cdot 5$ & $164 \cdot 5$ \\
Total anions & $172 \cdot 0$ & $172 \cdot 7$ & $172 \cdot 0$ & $162 \cdot 3$ & $183 \cdot 0$ & $172 \cdot 0$ & $194 \cdot 0$ \\
Total ions & $324 \cdot 5$ & $325 \cdot 2$ & $324 \cdot 5$ & $316 \cdot 8$ & $335 \cdot 5$ & $336 \cdot 5$ & $358 \cdot 5$ \\
Glucose & 5 & 5 & 5 & 5 & 5 & 5 & 5 \\
\hline \hline
\end{tabular}

Scientific Ltd). Sodium and potassium concentrations were determined by flame photometry (Corning 400) and $\mathrm{P}_{\mathrm{i}}$ concentrations were determined by spectrophotometry, with absorbance monitored at 340-380 nm (Cobas Mira; Roche).

\section{Expt 1. Mineral absorption from the isolated reticulo-rumen}

Seven sheep were used for this experiment, which consisted of a series of subsections in which mineral absorption rates were compared using solutions of two differing $P_{i}$ concentrations. In each subsection the effect of the solution with the lowest $P_{i}$ concentration $(2 \mathrm{mmol} / \mathrm{l})$ was compared to that with the higher $\mathbf{P}_{1}$ concentration. This was $8 \cdot 7,14.0$ or $17.3 \mathrm{mmol} \mathrm{P}_{\mathrm{i}} / \mathrm{l}$, depending on the experimental subsection. Thus, with any one sheep in one experimental day, two solutions of $2 \mathrm{mmol} \mathrm{P}_{\mathrm{i}} / \mathrm{l}$ were studied, followed by two solutions of either 8.7 or 14.0 or $17.3 \mathrm{mmol} \mathrm{P}_{\mathrm{i}} / 1$.

Further subsections of this experiment included the use of three sheep in which two measurements of mineral absorption rates from a solution containing $2 \mathrm{mmol} \mathrm{P}_{\mathrm{i}} / 1$ were made, followed by two sets of measurements using $38 \mathrm{mmol} \mathrm{P}_{\mathrm{i}} / 1$ solutions. The latter concentration might be expected during phosphate supplementation.

The reasons for duplicating each solution were twofold. First, it allowed the experimenter to detect any residual effects of a previous solution of differing composition, and second it provided a safeguard against total loss of results from a treatment caused by a burst Foley catheter cuff.

\section{Expt 2. Rumen $P_{i}$ concentrations}

Rumen contents were withdrawn via a large rumen fistula from five sheep fed on either a commercial pelleted diet plus hay or a frozen spring grass diet. The rumen contents were strained through muslin cheesecloth. Some of the strained rumen fluid (SRF) was analysed and some was centrifuged at $30000 \mathrm{~g}$ and the supernatant fraction analysed for $\mathrm{P}_{\mathrm{i}}$.

\section{RESULTS \\ Expt 1}

Comparison of the net $P_{i}$ absorption rates from the rumen buffered solutions showed that the $P_{i}$ absorption rate increased as the intraruminal $P_{\mathfrak{f}}$ concentration was increased from 2 to $8 \cdot 7,14$ and $17 \cdot 3 \mathrm{mmol} / 1$ (Fig. 1). 


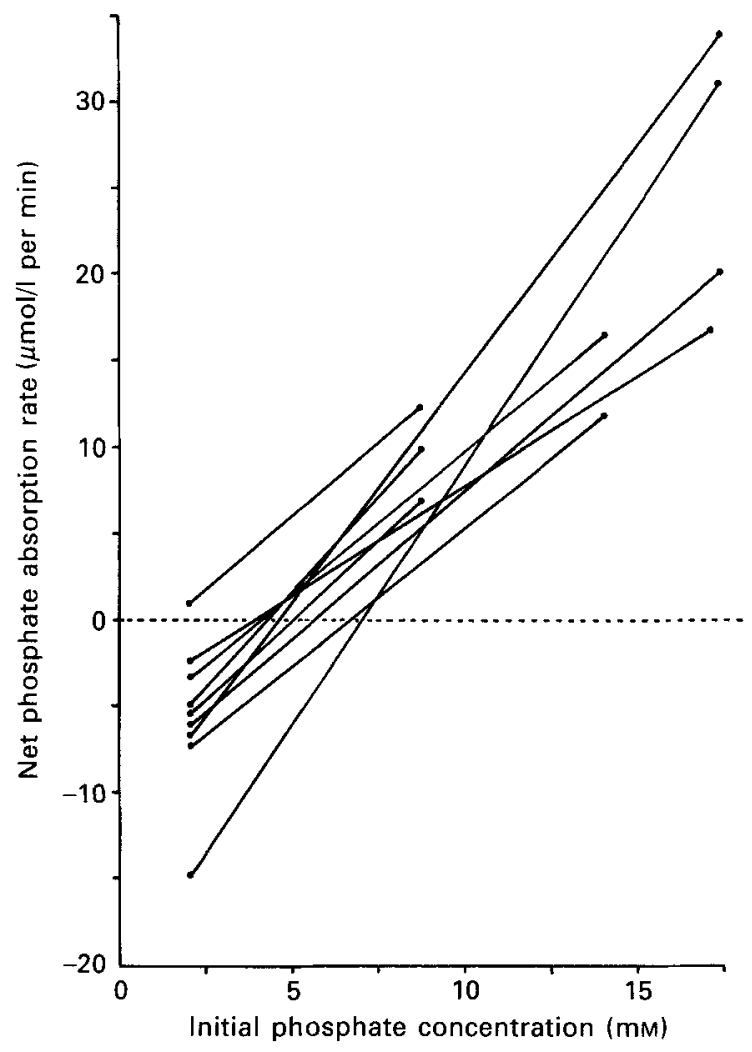

Fig. 1. Expt 1. The average net phosphate absorption rates $(\mu \mathrm{mol} / 1$ per $\mathrm{min})$ for individual sheep over a range of initial phosphate concentrations in the rumen solution (for details of procedures, see pp. 715-717).

Similarly, the net $\mathrm{Ca}$ absorption rate from the rumen solutions increased as the $\mathrm{P}_{\mathrm{i}}$ concentration in the solution was increased from 2 to $8.7,14$ and $17.3 \mathrm{mmol} / 1$ (Fig. 2).

Comparison of net $\mathrm{Mg}$ absorption rates from the rumen buffers showed that the $\mathrm{Mg}$ absorption rate was greater when the $P_{i}$ concentration in the buffer was increased from 2 to 8.7 and $17.3 \mathrm{mmol} / \mathrm{l}$ (Fig. 3). The variation between animals in this $\mathrm{Mg}$ response to increasing $\mathbf{P}_{\mathrm{i}}$ concentration was greater than that noted for $\mathrm{Ca}$ and $\mathbf{P}_{\mathrm{i}}$.

Conversely, the transmural PD associated with these rumen solutions tended to be consistently lower when the $P_{1}$ concentration in the solution was increased from 2 to 8.7 , 14 and $17 \cdot 3 \mathrm{mmol} / \mathrm{l}$ (Fig. 4).

Preliminary studies with two sheep showed that qualitatively similar changes in $\mathrm{P}_{\mathrm{i}}$, $\mathrm{Ca}$ and $\mathrm{Mg}$ absorption rates occurred when the rumen $\mathrm{P}_{i}$ concentration was increased in the presence of a high $\mathrm{K}$ concentration, $90 \mathrm{mmol} / 1$.

The $\mathrm{P}_{\mathrm{i}}$ absorption rates from the rumen increased in all three sheep studied as the rumen $\mathrm{P}_{\mathrm{i}}$ concentration was increased from 2 to $38 \mathrm{mmol} / \mathrm{l}$, i.e. from -2.8 to $19.9,-2.9$ to 57.7 and -2.5 to $3.0 \mu \mathrm{mol} / 1$ per min. Similarly, the $\mathrm{Ca}$ absorption rates were increased, i.e. from 0.4 to $18 \cdot 4,2.7$ to 15.7 and -4.5 to $2.5 \mu \mathrm{mol} / 1$ per min. In contrast, the $\mathrm{Mg}$ absorption rates decreased in all three sheep, i.e. from 10.5 to $9 \cdot 8,11 \cdot 1$ to 8.3 and 4.8 to $1.7 \mu \mathrm{mol} / 1$ per $\mathrm{min}$. In the two sheep monitored, the rumen transmural PD decreased, i.e. from 29.6 to 25.6 and $42 \cdot 8$ to $35 \cdot 9 \mathrm{mV}$. 


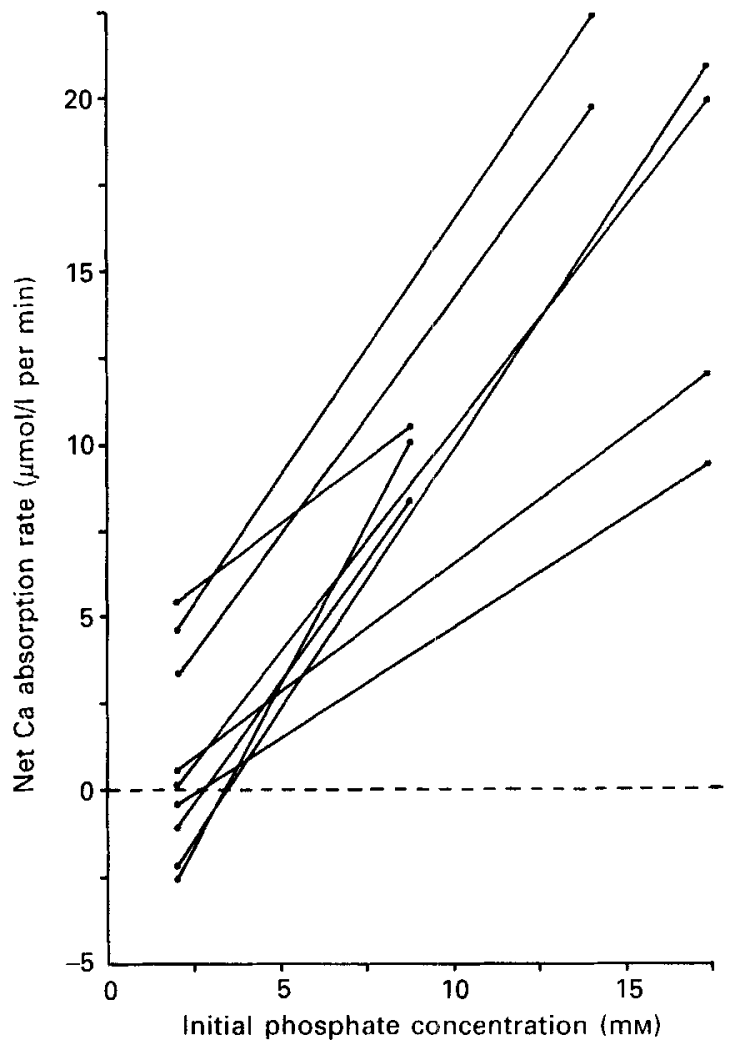

Fig. 2. Expt 1. The net calcium absorption rates ( $\mu \mathrm{mol} / 1$ per $\mathrm{min})$ for individual sheep over a range of initial phosphate concentrations in the rumen solution (for details of procedures, see pp. 715-717).

Table 2. Expt 2. The inorganic phosphate $\left(P_{i}\right)$ concentration in fractions of rumen contents from sheep fed on different diets

\begin{tabular}{|c|c|c|c|}
\hline \multirow[b]{2}{*}{ Diet* } & \multirow[b]{2}{*}{ Rumen fraction } & \multicolumn{2}{|c|}{$\mathrm{P}_{\mathrm{i}}(\mathrm{mmol} / \mathrm{l})$} \\
\hline & & Mean & SEM \\
\hline Hay + pellets & Strained rumen fluid & $26 \cdot 03$ & $2 \cdot 51$ \\
\hline Frozen grass & Strained rumen fluid & $13 \cdot 00$ & $2 \cdot 83$ \\
\hline Hay + pellets & $\begin{array}{l}\text { Pooled sample of } 30000 \mathrm{~g} \\
\text { supernatant fraction }\end{array}$ & $19 \cdot 76$ & - \\
\hline Frozen grass & $\begin{array}{l}\text { Pooled sample of } 30000 \mathrm{~g} \\
\text { supernatant fraction }\end{array}$ & $15 \cdot 52$ & - \\
\hline
\end{tabular}

* For details, see p. 716.

Expt 2. Rumen $P_{i}$ concentrations

The $P_{i}$ concentrations in SRF and in a $30000 \mathrm{~g}$ centrifugate of SRF were determined from rumen contents of sheep fed on either a commercial pellet and chopped hay diet or frozen spring grass, each sampled $6 \mathrm{~h}$ post feeding.

The $P_{i}$ concentrations in the SRF from sheep fed on different diets were markedly different, the frozen spring grass being lower (Table 2). Similarly, the $\mathbf{P}_{i}$ concentration in 


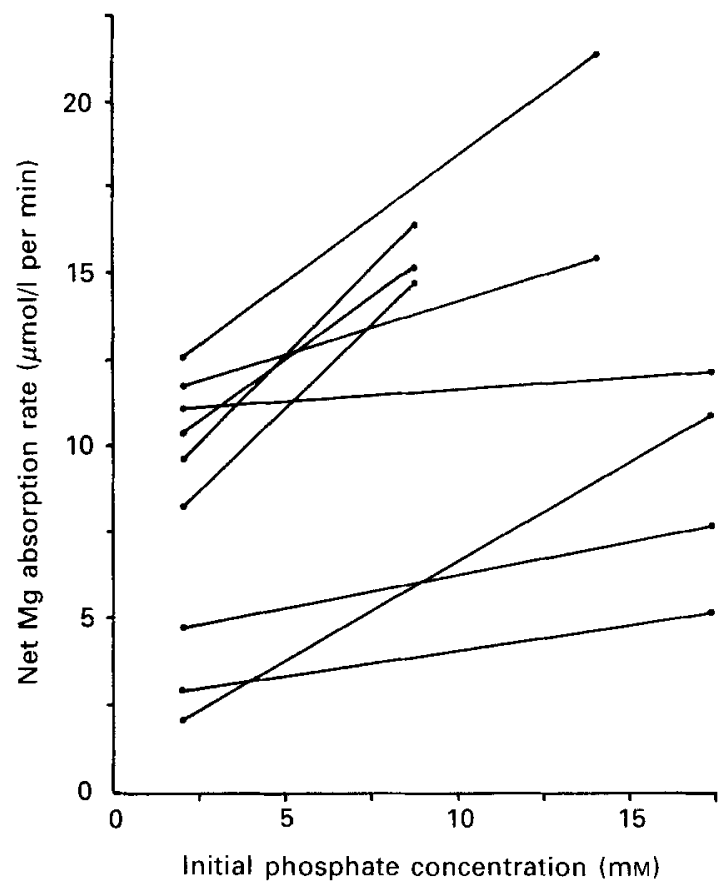

Fig. 3. Expt 1. The average net magnesium absorption rates ( $\mu \mathrm{mol} / 1$ per min) for individual sheep over a range of initial phosphate concentrations in the rumen solution (for details of procedures, see pp. 715-717).

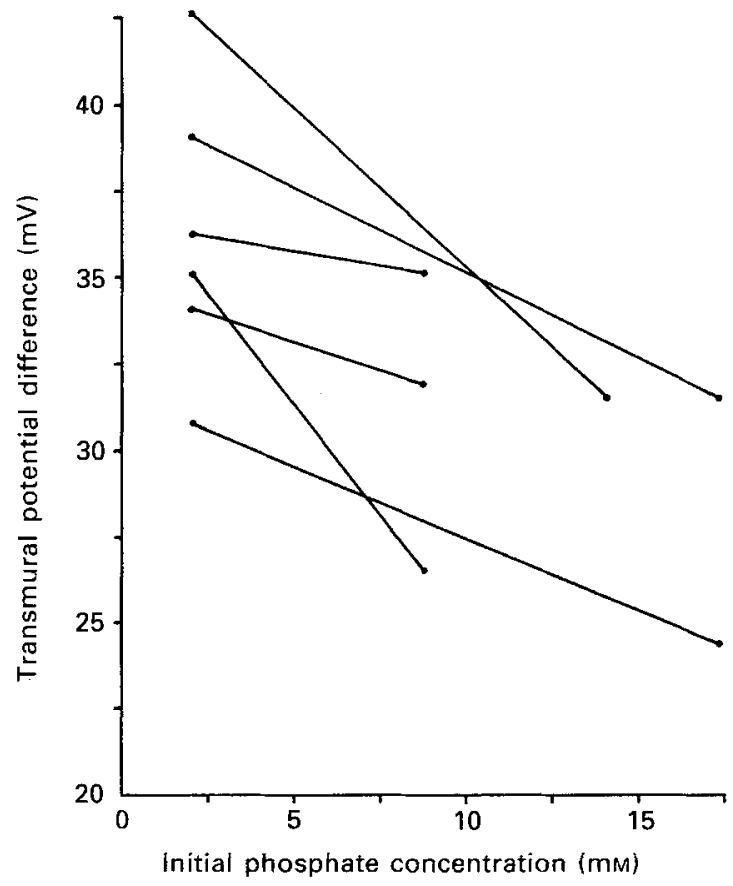

Fig. 4. The transmural potential difference $(\mathrm{mV})$ blood positive for individual sheep over a range of initial phosphate concentrations in the rumen solution (for details of procedures, see pp. 715-717). 
the supernatant fraction obtained by centrifuging the grass SRF at $30000 \mathrm{~g}$ was lower than that in the other supernatant fraction. Both values were found to be within the range of $P_{i}$ concentrations used (Table 1).

\section{DISCUSSION}

Recent evidence has highlighted the role of the rumen as an organ for $\mathrm{P}_{\mathrm{i}}$ absorption (Breves \& Holler, 1986; Breves et al. 1986, 1988). Although earlier workers demonstrated the ability of the rumen epithelium to transport $P_{i}$ in both directions (Scarisbrick \& Ewer, 1951; Parthasarathy et al. 1952; Sperber \& Hydén, 1952; Wright, 1955), the results varied considerably, and the conclusion drawn was that substantial net $\mathrm{P}_{\mathrm{i}}$ transfer does not occur across the rumen wall, although this epithelium is capable of transporting both ${ }^{32} \mathrm{P}$ or unlabelled $\mathrm{P}_{\mathrm{i}}$ down a concentration gradient under a variety of conditions. Similarly, Scott \& Buchan (1987) were unable to support the theory that ${ }^{32} \mathrm{P}_{\mathrm{i}}$ is transported across any part of the forestomach epithelium of sheep, although ${ }^{32} \mathrm{P}_{\mathrm{i}}$ does appear in the plasma when the digesta is allowed to pass into the small intestine. The results of Scott \& Buchan (1987) are not compatible with the results presented in the present paper or with those of Breves \& Holler (1986) or Breves et al. (1988). The reason for this is unclear, but it may be attributable to the differences in experimental technique. The most obvious difference is the use of inorganic buffers by Breves et al. $(1986,1988)$ and ourselves, whereas Scott \& Buchan (1987) studied ${ }^{32} \mathrm{P}_{1}$ absorption from digesta. There is a possibility that the ${ }^{32} \mathrm{P}_{\mathrm{i}}$ may have been bound by digesta. However, we did not find this to be so (L. Beardsworth, P. Beardsworth and A. Care, unpublished results) and Scarisbrick \& Ewer (1951) have observed ${ }^{32} \mathbf{P}_{\mathrm{i}}$ transfer from rumen digesta to the rumen vein. Without further information on the $\mathrm{pH}, \mathrm{P}_{\mathrm{i}}, \mathrm{Ca}$ and ammonia concentrations in the digesta, the possibility of the ${ }^{32} \mathbf{P}_{\mathrm{i}}$ becoming unavailable for absorption because of binding to digesta cannot be decided.

It has been demonstrated in vitro and in vivo that $P_{i}$ absorption across the rumen wall increases as the rumen $P_{i}$ concentration is increased (Breves et al. 1986, 1988). We have confirmed this, and our results indicate that net $P_{i}$ absorption occurs only at $P_{i}$ concentrations above a mean of $4.3 \mathrm{mmol} / 1$ (Fig. 1). This agrees well with the value of $4 \cdot 1 \mathrm{mmol} / 1$ from Breves et al. (1988). The rumen $P_{1}$ concentration has been shown to vary with the diet (Table 2). On a diet containing only $2 \cdot 2 \mathrm{~g} \mathrm{P} / \mathrm{kg}$ dry matter, Grings \& Males (1987) reported that the rumen supernatant-fraction $P_{i}$ concentration was still within the range $16-20 \mathrm{mmol} / 1$, despite the suboptimal $\mathrm{P}$ intake. Conversely, Breves et al. (1987) showed that a decrease of $85 \%$ in the $P_{1}$ concentration within the rumen was associated with a $60 \%$ decrease in total daily salivary $\mathrm{P}$ output (from 6.25 to $2.4 \mathrm{~g}$ ) caused by the ingestion of a P-deficient diet $(0.96 \mathrm{~g} \mathrm{P} / \mathrm{d}$ compared with $4.2 \mathrm{~g} \mathrm{P} / \mathrm{d}$ in control sheep).

The results of the present study indicate that at normal physiological rumen $P_{1}$ concentrations, i.e. $16-20 \mathrm{mmol} / 1$ (Table 2), the capacity of the rumen to absorb $\mathrm{Ca}$ is greatly enhanced relative to that at $P_{i}$ concentrations compatible with induced $P$ depletion, i.e. $2 \mathrm{mmol} / \mathrm{l}$ (G. Breves, personal communication). The effect on $\mathrm{Mg}$ absorption rate was similar but occurred to a lesser extent. Preliminary studies showed that the effect on $\mathrm{Ca}$ absorption was maintained up to $\mathrm{P}_{\mathrm{i}}$ concentrations of $38 \mathrm{mmol} / \mathrm{l}$, but $\mathrm{Mg}$ absorption was reduced at that $P_{i}$ concentration. It should be noted that as the $P_{i}$ concentration of the intraruminal solution was increased from 2 to $17.3 \mathrm{mmol} / \mathrm{l}$, the ionized Ca concentration decreased from 1.66 (SE 0.04) to 1.20 (SE 0.04) mmol/1, despite a fall in $\mathrm{pH}$ from 6.60 to 6.19 , and without a change in total $\mathrm{Ca}$ concentration. This observation indicated that the increased $\mathrm{Ca}$ absorption rate observed under conditions of increased $\mathrm{P}_{\mathrm{i}}$ concentration could not be attributed to an increase in the ionized $\mathrm{Ca}$ concentration within the $17 \cdot 3 \mathrm{mmol}$ $\mathrm{P}_{\mathrm{i}} / \mathrm{l}$ solution. The mechanism of $\mathrm{Ca}$ transport across the rumen wall is unknown, but it may 
be similar to the coupled $\mathrm{Ca}-\mathrm{P}_{\mathrm{i}}$ transport which may be present in rat small intestine (Walling, 1977). The observation that the $\mathrm{Ca}$ absorption rate is not decreased as the transmural PD is increased by a high intraruminal $\mathrm{K}$ concentration (Beardsworth et al. 1987 ) would suggest that the process of $\mathrm{Ca}$ absorption across the rumen wall is mainly active.

The results from these experiments suggest that the maintenance of $\mathrm{P}$ repletion in grazing animals is likely to facilitate the absorption of $\mathrm{P}_{\mathrm{i}}$ and $\mathrm{Ca}$ from the rumen. This is also true to a lesser extent for $\mathrm{Mg}$. Acute clinical hypomagnesaemia (grass tetany) is often accompanied by hypocalcaemia, and it has been reported that many hypomagnesaemic animals may appear normal until clinical symptoms are triggered by a further factor, commonly hypocalcaemia (Hemingway \& Ritchie, 1965). Hypophosphataemia has also been reported to be associated with clinical hypomagnesaemia. That is, animals turned out to spring pasture may be exposed not only to an increased intake of $\mathrm{K}$ but to a decreased $\mathrm{P}$ intake, which may result in decreased absorption of $\mathrm{Ca}, \mathrm{Mg}$ and $\mathrm{P}_{\mathrm{i}}$ from the rumen. On the other hand, it appears that if $P$ supplementation were able to produce a very high rumen $P_{i}$ concentration $(38 \mathrm{mmol} / \mathrm{l}$ ) there might be interference with $\mathrm{Mg}$ absorption from the rumen. At such high levels, even at the acidic $\mathrm{pH}$ of the rumen, precipitation of guanite $\left(\mathrm{MgNH}_{4} \mathrm{PO}_{4} \cdot 6 \mathrm{H}_{2} \mathrm{O}\right)$ may begin to occur (Axford et al. 1982).

The present study highlights the potential importance of preventing $\mathrm{P}$ deficiency in the grazing ruminant which may be susceptible to hypocalcaemia and hypomagnesaemia. It indicates that an intraruminal $P_{i}$ concentration of $15-20 \mathrm{mmol} / 1$ is desirable to improve the absorption of $\mathbf{P}_{\mathrm{i}}, \mathrm{Ca}$ and $\mathrm{Mg}$ across the rumen wall.

The financial assistance of the Australian Meat and Livestock Research and Development Corporation is gratefully acknowledged.

\section{REFERENCES}

Axford, R. F. E., Hughes, A. \& Evans, R. A. (1982). Magnesium ammonium phosphate precipitation and its significance in sheep. Proceedings of the Nutrition Society 41, 85A.

Beardsworth, L. J., Beardsworth, P. M. \& Care, A. D. (1987). The effect of increased potassium concentration on the absorption of magnesium from the reticulo-rumen of conscious sheep. Journal of Physiology 386, 89P.

Breves, G., Gabel, G., Martens, H. \& Holler, H. (1986). Phosphate fluxes across the rumen wall mucosa of sheep in vitro. Proceedings of the Nutrition Society 45, 99A.

Breves, G. \& Holler, H. (1986). Nettoresorption von anorganischem phosphat aus dem Pansen von Schafen. Journal of Animal Physiology and Nutrition 56, 159.

Breves, G., Holler, P., Packheiser, P., Gabel, G. \& Martens, H. (1988). Flux of inorganic phosphate across the sheep rumen wall in vivo and in vitro. Quarterly Journal of Experimental Physiology 73, 343-351.

Breves, G., Rosenhagen, C. \& Holler, H. (1987). Die Sekretion von anorganischem Phosphor mit dem Speichel bei P-depleterton Schafen. Zentralblatt für Veterinär-Medizin 34, 42-47.

Care, A. D., Brow ', R. C., Farrar, A. R. \& Pickard, D. W. (1984). Magnesium absorption from the digestive tract of sheep. Quarterly Journal of Experimental Physiology 69, 577-587.

Dobson, A. (1959). Active transport through the epithelium of the reticulo-rumen sac. Journal of Physiology 146, $235-251$.

Dobson, A., Sellers, S. F. \& Gatewood, V. H. (1976). Dependence of CrEDTA absorption from the rumen on luminal osmotic pressure. American Journal of Physiology 231, 1595-1600.

Downes, A. M. \& McDonald, I. W. (1964). The chromium-51 complex of ethylenediamine tetraacetic acid as a soluble rumen marker. British Journal of Nutrition 18, 153-162.

Edrise, B. M. \& Smith, R. H. (1986). Exchanges of magnesium and phosphorus at different sites in the ruminant stomach. Archives of Animal Nutrition, Berlin 36, 1019-1027.

Grace, N. D., Caple, I. W. \& Care, A. D. (1988). Studies in sheep on the absorption of magnesium from a lowmolecular-weight fraction of the reticulo-rumen contents. British Journal of Nutrition 59, 93-108.

Grings, E. E. \& Males, J. R. (1987). Effects of potassium macromineral absorption in sheep fed wheat straw-based diets. Journal of Animal Science 64, 872-879.

Hemingway, R. G. \& Ritchie, N. S. (1965). The importance of hypocalcaemia in the development of hypomagnesaemic tetany. Proceedings of the Nutrition Society 24, 54. 
Martens, H. \& Rayssiguier, Y. (1980). Magnesium metabolism and hypomagnesaemia. In 5th International Symposium on Ruminant Physiology, pp. 447-466 [Y. Ruckebusch and P. Thivend, editors]. Lancaster: MTP Press.

Parthasarathy, D., Garton, G. A. \& Phillipson, A. T. (1952). The passage of phosphorus across the rumen epithelium of sheep. British Journal of Nutrition 52, xvi-xvii.

Ritchie, N. S. \& Fishwick, G. (1977). Magnesium phosphate as a dietary supplement for lactating cows at spring pasture. Journal of Agricultural Science, Cambridge 88, 7!-73.

Scarisbrick, R. \& Ewer, T. K. (1951). The absorption of inorganic phosphate from the rumen of sheep. Biochemical Journal 49, xxix.

Scott, D. \& Buchan, W. (1987). The effects of feeding either hay or grass diets on salivary phosphorus secretion, net intestinal phosphorus absorption and on the partition of phosphorus excretion between urine and faeces in the sheep. Quarterly Journal of Experimental Physiology 72, 331-333.

Simesen, M. G. (1970). Calcium, inorganic phosphorus and magnesium metabolism in health and disease. In The Clinical Biochemistry of Domestic Animals, pp. 3 I3-375 [.J. J. Kaneko and C. E. Cornelius, editors]. New York: Academic Press.

Sperber, I. \& Hydén, S. (1952). Transport of chloride through the ruminal mucosa. Nature 169, 587.

Walling, M. W. (1977). Intestinal Ca and phosphate transport: differential responses to vitamin $\mathrm{D}_{3}$ metabolites. American Journal of Physiology 233, E488-E494.

Wright, E. (1955). Site of phosphorus absorption in the sheep. Nature 176, 351-352. 